\title{
Artículos
}

\section{La conformación de hogares con hijos en México: el papel del ingreso, la edad y la desigualdad salarial}

\author{
Households with children in Mexico: \\ The role of income, age and wage inequality
}

Ignacio Ibarra López*

\section{Resumen}

Se utilizan datos de la Encuesta Nacional de Ingresos y Gastos de los Hogares en México de diferentes años (2006, 2008, 2010, 2012 y 2014) para conocer el efecto del ingreso y la edad en la forma en cómo se conforman hogares con hijos en México de acuerdo con el tipo de jefatura (hombre o mujer). Un primer hallazgo es que se prefiere generar hogares tradicionales donde las personas se casan para tener hijos. Adicionalmente, se reporta un fuerte vínculo de la desigualdad de ingresos entre mujeres y hombres y el establecimiento de un hogar tradicional.

Palabras clave: hogar monoparental; fertilidad; desigualdad de ingresos; matrimonio.

\begin{abstract}
Data from the National Survey of Household Income and Expenditure in Mexico for different years (2006, 2008, 2010, 2012 and 2014) are used to know the effect of income and age on conformation of households with children in Mexico. One of our findings is that it is preferred to generate traditional households to another type of household. Another worrying regularity is that there is a strong link between income inequality and the establishment of a traditional household.
\end{abstract}

Keywords: monoparental household; fertility; income inequality; marriage.

* Instituto Tecnológico y de Estudios Superiores de Monterrey, campus Puebla, Departamento de Economía. Dirección postal: Atlixcáyotl 5718, Reserva Territorial Atlixcáyotl, 72453, Puebla, Pue., México. Correo electrónico: iibarral@tec.mx ORCID: https://orcid.org/00000002-0371-3976 


\section{Introducción}

Mediante el análisis de la serie histórica de las estadísticas de natalidad por tipo de situación conyugal de las mujeres (1985 a 2016) del Instituto Nacional de Estadística y Geografía (INEGI), ${ }^{1}$ se observan algunas tendencias importantes (véase la Gráfica 1). Por ejemplo, tomando como referencia 1985, se tenía que $7.25 \%$ de los nacimientos los concentraban solteras, $68.99 \%$ casadas (por lo civil o religioso), $19.71 \%$ en unión libre y $0.18 \%$ divorciadas o separadas. Para el año 2016, 12.37\% de los nacimientos ocurren cuando la mujer es soltera, $30.38 \%$ se relacionan con mujeres casadas, pero $49.25 \%$ ocurren cuando las mujeres se encuentran en unión libre. Un total de $0.35 \%$ de nacimientos se verifican en mujeres que están separadas o divorciadas.

Lo anterior implica que a lo largo del tiempo las mujeres en México han preferido tener hijos en formas alternativas al matrimonio convencional. También revela un incremento lento pero consistente de la proporción de nacimientos donde existe un hogar monoparental con jefatura femenina (i.e., madre soltera).

La aparición del hogar monoparental (HM) en México no es un tema nuevo de estudio, como se expresa en diferentes trabajos (Esteinou, 2014; Ariza y De Oliveira, 2006; García y Rojas, 2002; Landero, 2001; Welti Chanes, 2000; González-De la Rocha, 1999; López e Izazola, 1994; Tuirán, 1993). Sin embargo, hasta donde se conoce, no se ha explorado si el ingreso y la desigualdad de ingresos son motivaciones que tienen las personas para establecer este tipo de hogares. Esto puede ocurrir porque en la literatura sobre México y Latinoamérica se ha considerado que las personas que forman un hogar monoparental tienen cierto perfil: bajo ingreso, mala educación (Landero, 2001; González-De la Rocha, 1999), posiblemente pertenecen a su vez a un hogar monoparental, y son adolescentes o jóvenes (González y Molina, 2007).

En este sentido, el presente trabajo hace una aportación a la literatura al probar dos ideas con datos del país: 1) a medida que las mujeres tienen mejores ingresos, deciden establecer un hogar monoparental, como ocurre en los países europeos (Liefbroer y Corijin, 1999), y 2) observa si el cambio en la desigualdad de ingresos entre mexicanas y mexicanos tiene algún efecto en la formación de hogares monoparentales, como lo plantean Gibson-Davis (2011) y Smith-Battle (2000).

1 Para revisar los datos de 1970, véase http://www3.inegi.org.mx/sistemas/sisept/Default. aspx?t=mdemo $77 \& \mathrm{~s}=\mathrm{est} \& \mathrm{c}=23571$. También se recomienda revisar el microdato disponible en http://www.beta.inegi.org.mx/proyectos/registros/vitales/nupcialidad/ 


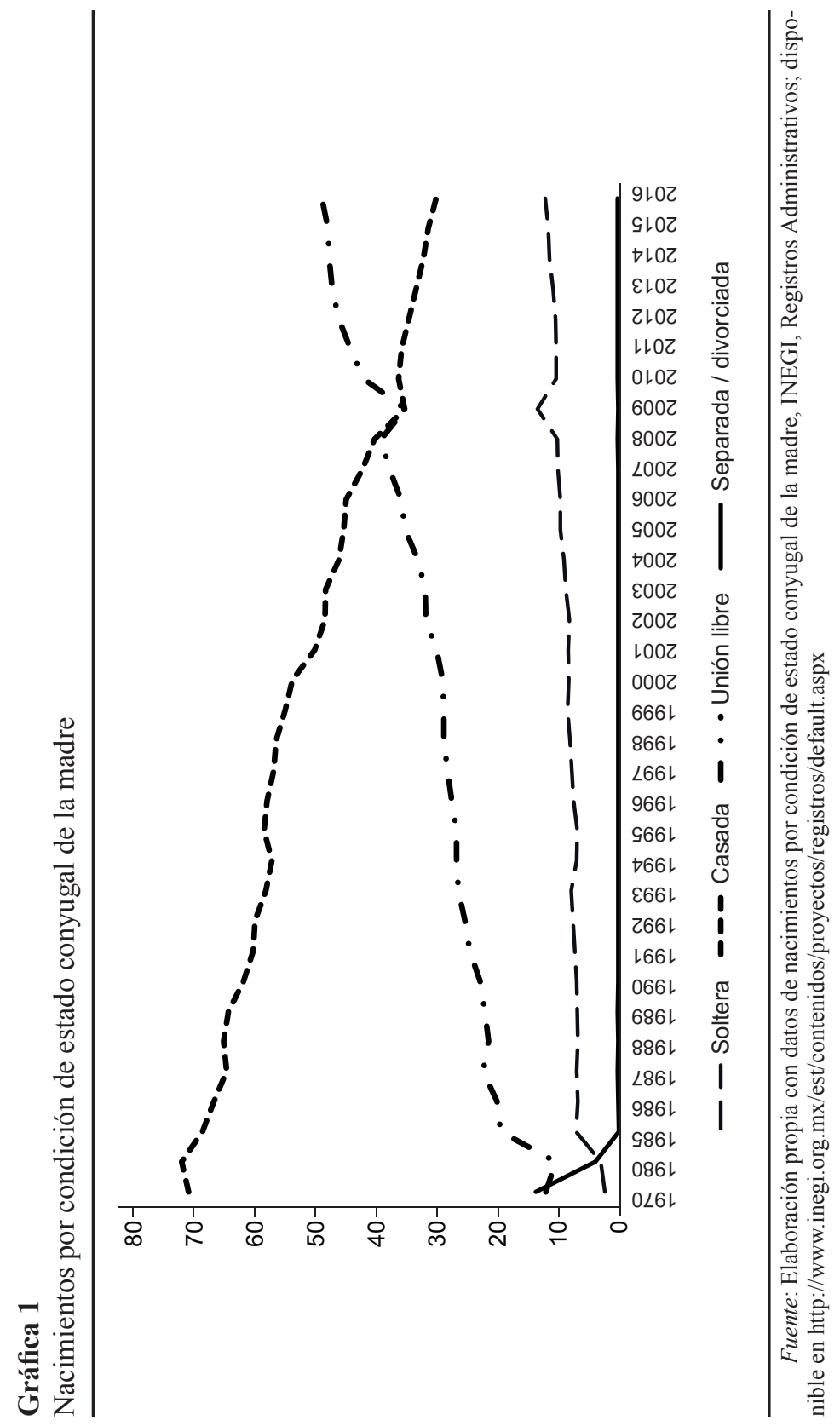


Como estrategia de análisis, se plantea medir el impacto del ingreso y la edad en tres diferentes tipos de hogares: 1) monoparentales, 2) tradicionales con hijos, y 3) hogares que viven en pareja con hijos. Se utiliza información oficial de la Encuesta Nacional de Ingresos y Gastos en los Hogares (ENIGH) para los años 2006, 2008, 2010, 2012 y 2014.

En términos teóricos, el modelo Calidad-Cantidad de Becker y Lewis (1973) es un punto de partida para entender la decisión de casarse y tener hijos. A continuación, se presentan los argumentos de dicho modelo, incorporando posteriormente hallazgos sobre la fertilidad y el matrimonio que tienen un enfoque más sociológico (Hakim, 2000, 2003, 2006; Vitali, Billari, Prskawetz y Testa, 2009).

\section{La decisión de tener hijos}

Desde la arista económica tradicional (Becker y Lewis, 1973; Becker, 1981, p. 143), se piensa que las personas al casarse establecen un contrato donde obtienen un beneficio derivado de la especialización de labores (Becker, 1974). Se asume que en una sociedad existen actividades económicas (i.e., remuneradas) y actividades no económicas (i.e., no remuneradas), las cuales pueden ser realizadas por los integrantes de la pareja. Bajo este planteamiento, un matrimonio es una solución para establecer quién se dedica a cada actividad, tomando como punto de partida la desigualdad salarial que persiste de forma sistemática en contra de las mujeres. Si ellas ganan menos que los hombres al realizar las mismas actividades económicas, entonces, al tener hijos existe una presión para que empleen su tiempo en actividades no económicas, tales como las labores del hogar y el cuidado de los hijos. Si los hombres ganan más que las mujeres por realizar actividades económicas, entonces se deberían dedicar a trabajar fuera del hogar y mediante su ingreso mantener a toda la familia.

En cuanto a la decisión de tener hijos, el modelo denominado CC (Calidad-Cantidad) propone una relación entre la cantidad de hijos y la calidad, vista como los gastos realizados por los padres en cada hijo. Así, se tiene un hijo adicional hasta el punto en que no se compromete la calidad con la cual se atiende a todos. El supuesto que prevalece es que los padres buscan dar siempre a cada hijo lo mismo, y mientras obtengan más ingresos, es posible tener más hijos sin comprometer demasiado lo que se otorga a los demás.

Blake (1968) rebate este argumento indicando que si en una sociedad desarrollada las personas conocen los métodos anticonceptivos, debería 
observarse que los pobres tienen menos hijos y los ricos más hijos. Como esto no ocurre, no se puede concluir que la demanda de hijos no está bajo el control monetario, al igual que los demás bienes que se intercambian en un mercado.

Otra cuestión controversial con Becker es que en sus modelos la decisión de formar o no un hogar no incorpora las relaciones de poder y los conflictos que surgen entre las personas recurriendo al teorema del niño malcriado (Becker, 1974, 1981). ${ }^{2}$ Derivado de este teorema, los integrantes de un hogar terminan alineando sus decisiones en torno a las decisiones del jefe, simplemente porque éste tiene el poder económico para imponer condiciones a los demás miembros.

A pesar de estas críticas, el modelo CC corresponde a un periodo histórico específico y pudiera ser adecuado para explicar el comportamiento de las personas al formar un hogar en función del ingreso. Particularmente, en sociedades donde la brecha de ingresos entre hombres y mujeres es grande, prevalece una organización patriarcal. Esta situación se observa para el caso de México.

\section{Ingreso, educación y relaciones de poder en una familia}

Las familias tienen diferentes arreglos para tomar decisiones $y$, como se ha demostrado en algunos trabajos (Bergstrom, 1989; Lindbeck y Weibull, 1988), es difícil sostener de forma realista que no existan conflictos en un hogar al amparo del teorema del niño malcriado. En particular, se ha observado que precisamente una de las causas para la aparición de conflicto consiste en las diferencias de los padres en relación con la cantidad de hijos que deciden tener (Browning, Chiappori y Weiss, 2014).

También se ha encontrado que, ante un aumento en el ingreso que perciben las mujeres que trabajan, existe una motivación para que permanezcan solteras y para retrasar la maternidad a cambio de alcanzar metas laborales o salariales (Ellwood y Jencks, 2004; Edin, 2000; DiPrete y Buchmann, 2006). Cuando las mujeres obtienen poder dentro del hogar, se compromete la estabilidad de la pareja, ya que el hombre puede tener incentivos para no

2 Dicho teorema implica que los integrantes de un hogar derivan beneficios a partir del ingreso del jefe, al cual le importa el beneficio de los demás. Si existe un niño malcriado que podría obtener placer al imponer costos o dañar a un integrante, el jefe del hogar compensará económicamente a la persona afectada, quitándole recursos al niño malcriado. La transferencia de recursos compensa el daño hacia la víctima y permite al jefe del hogar mandar una señal de que no es posible el conflicto dentro del hogar. Becker asume que la señal es capaz de disuadir a todos los integrantes que pudieran querer ser malvados. 
casarse o separarse en la medida en que no ejerce el control absoluto del hogar (Edin, 2000).

Una variable que se encuentra correlacionada con el ingreso es la educación. Al respecto, se ha identificado que las mujeres más educadas tienen mayor control sobre su maternidad (Rivas, Jociles y Moncó, 2011). La evidencia para los países nórdicos en particular, demuestra que las mujeres con niveles altos de educación posponen la decisión de tener hijos debido a que también buscan una mejor posición laboral (Nicoletti y Tanturri, 2008; Lappegård y Rønsen 2005; Meron y Widmer, 2002).

Por lo tanto, si bien no es una condición generalizada, se podría esperar que tanto el nivel de ingreso como el grado de estudios incida positivamente en la existencia de hogares monoparentales (Liefbroer y Corijin, 1999; Martin y Juárez, 1995). A continuación se profundiza sobre esta idea.

\section{Modelo Calidad-Cantidad en México: la importancia de la desigualdad}

A pesar de los cambios experimentados a nivel mundial en cuanto a los roles que deben desempeñar mujeres y hombres en un hogar, en el ámbito familiar mexicano subsiste la idea de que el hombre trabaja y la mujer se queda en casa. Diversas unidades de gobierno en México han concluido que: "La distribución de las tareas domésticas en el interior del hogar reflejan y reproducen cotidianamente los roles de género, en los cuales, en general, la mujer es confinada al mundo privado del trabajo doméstico y el hombre al mundo público y de proveedor" (Conapo, 2009, p. 140).

En el modelo de Becker, la desigualdad de ingresos entre hombres y mujeres es el origen de la división de tareas dentro y fuera del hogar. A medida que una sociedad se vuelve más igualitaria, puede surgir el conflicto dentro de un hogar y es posible el establecimiento de hogares alternativos al hogar tradicional.

Por ejemplo, Smith-Battle (2000) reporta que la desigualdad de ingresos entre hombres y mujeres incide positivamente en la conformación de hogares tradicionales (biparentales con jefatura masculina). Dicho de otra forma: mientras más desigual es una sociedad con sus mujeres en el mercado laboral, deberán existir más matrimonios.

Complementando este argumento, Gibson-Davis (2011) ha encontrado que una mejora en el ingreso de los hombres incrementa la cantidad de matrimonios en una sociedad. Simultáneamente, y al igual que Piani (2003), descubre que las mujeres con mejores oportunidades económicas tienen una 
menor probabilidad de estar casadas, y si están casadas son más propensas a divorciarse.

En México, la decisión de casarse puede ser vista como una estrategia de supervivencia para algunas mujeres. A medida que estas mujeres se incorporan al mercado laboral, pueden encontrar que el matrimonio o vivir con una pareja es una condición más costosa. Por lo tanto, los incentivos para emparejarse disminuyen, mientras que algunas de las mujeres que ya tienen pareja y trabajan podrían decidir vivir solas. Se ha observado evidencia de este comportamiento en países como Estados Unidos (Edin, 2000). ${ }^{3}$

Adicionalmente, el cambio de expectativas laborales, de ingreso y de empoderamiento para las mujeres genera un fuerte cambio en la sociedad, propiciando lo que en la literatura se identifica como emparejamiento selectivo, y en su grado más extremo como homogamia (López-Ruiz, Esteve y Cabré, 2009). Existe un emparejamiento selectivo cuando dos personas se unen tomando como criterio de selección rasgos significativos, ya sea por adscripción (etnia, raza) o socialmente adquiridos (educación, religión, ocupación). La homogamia implica que las características de los integrantes de una pareja son iguales o bastante similares. Cuando los integrantes de la pareja son muy diferentes se habla de heterogamia.

En los últimos años, se ha reportado que, principalmente en países como Estados Unidos, existe una relación entre el emparejamiento selectivo y la desigualdad de ingresos (Liu, 2015; Carbone y Cahn, 2014). En particular, Liu (2015) encuentra que, al establecer selectividad en el tipo de emparejamientos como una respuesta o estrategia a un entorno de desigualdad, se incide en el coeficiente de Gini de Estados Unidos. Si las personas con ingresos altos se unen a otras de ingresos también altos se concentran todavía más los ingresos, lo cual a su vez incrementa el Gini. ${ }^{4}$ Por ello, si en los años que analiza Liu

3 En su trabajo se cuestiona a las madres solteras (jefas de un hogar monoparental) en Estados Unidos sobre la importancia de establecer un matrimonio. La mayoría contesta que aceptaría casarse siempre que sus parejas potenciales tuvieran un ingreso mucho mayor al salario mínimo. Además hacen énfasis en la estabilidad del empleo, el origen de los ingresos y el esfuerzo que haga la pareja para mejorar y mantener su trabajo. Lo interesante es que, a la par de las variables asociadas con el tema salarial y el empleo, las madres solteras también consideran factores no monetarios, como que el matrimonio les otorga un estatus de respeto, el ganar o perder el control de las decisiones en el hogar, la desconfianza en los hombres y el miedo a la violencia doméstica. En el balance, las mujeres entrevistadas consideran que el matrimonio podría hacer más complicada su vida. La mayoría no percibe algún estigma al permanecer solteras. Todavía más interesante: indican que, si en el matrimonio no disfrutan de estabilidad económica y obtienen alguna ganancia en movilidad social, existen pocas razones para enfrentar el riesgo de perder el control de su hogar y enfrentar el miedo provocado por la violencia doméstica.

4 En el trabajo se realiza un ejercicio interesante para ilustrar el efecto del emparejamiento selectivo en la desigualdad: si se hubieran realizado emparejamientos entre hombres y mu- 
existieron emparejamientos aleatorios, hubiera sido posible que se redujera el Gini de manera significativa. También se ha encontrado en México evidencia del emparejamiento selectivo (Torche, 2010, 2015; López-Ruiz, Esteve y Cabré, 2009), sólo que en el análisis de la movilidad social.

Por lo anterior, la entrada al mercado laboral y la percepción de un mejor ingreso para las mujeres deben tener algún efecto en la cantidad de matrimonios e hijos que se tienen a nivel social. En la Gráfica 2 se analiza la relación entre las mujeres y los hombres que están en el mercado laboral y la relación de matrimonios y divorcios. Si casarse es una estrategia de supervivencia, se esperaría una relación positiva entre la razón mujeres / hombres en el mercado laboral y la razón divorcios / matrimonios.

Los datos indican que, a medida que transcurre el tiempo (de 2005 a 2016), hay una mayor participación de las mujeres en el mercado laboral mexicano. Por ejemplo, en el primer trimestre de 2005 se tenían casi 56 mujeres por cada 100 hombres, y en el cuarto trimestre se llega a 62 mujeres por cada 100 hombres. También se observa que la cantidad de divorcios en relación con el total de matrimonios aumenta, pues en 2005 se tuvieron 11.78 divorcios por cada 100 matrimonios, mientras que en 2016 la cifra llega a casi 26 divorcios. Por lo tanto, la entrada de más mujeres al mercado laboral mexicano ha sido suficiente para poder incidir en la cantidad de divorcios y matrimonios. Esto no implica que sea la única variable que explica el aumento en los divorcios y la caída en los matrimonios.

En cuanto al ingreso, éste se puede relacionar con la cantidad de hijos. La Gráfica 3 presenta un ejercicio muy sencillo pero ilustrativo con tres series: la proporción de hombres que en el mercado laboral mexicano obtienen ingresos de más de tres salarios mínimos (SM), la proporción de mujeres que en el mercado laboral obtienen ingresos de más de tres SM y la proporción de registros de nacimientos de dos hijos y más. Con claridad se observa que todas las series tienen pendiente negativa. En el caso de los hombres y el número de hijos, incluso se tienen intervalos parecidos.

Asumiendo la obligatoriedad de registrar los nacimientos, a medida que la proporción de personas en México con más de tres salarios disminuye, es menos probable que se registren más de dos hijos. Se debe destacar que la proporción de mujeres con tres SM y más siempre es menor a la de los hombres, lo cual implica la prevalencia de una enorme desigualdad salarial derivada del género. Este dato es importante debido a que Smith-Battle (2000) ha encontrado que la desigualdad de ingresos entre hombres y mujeres inci-

jeres al azar, en lugar de selectivos, para el año 2005 en Estados Unidos el coeficiente de Gini hubiera caído de 0.43 a 0.34 . 


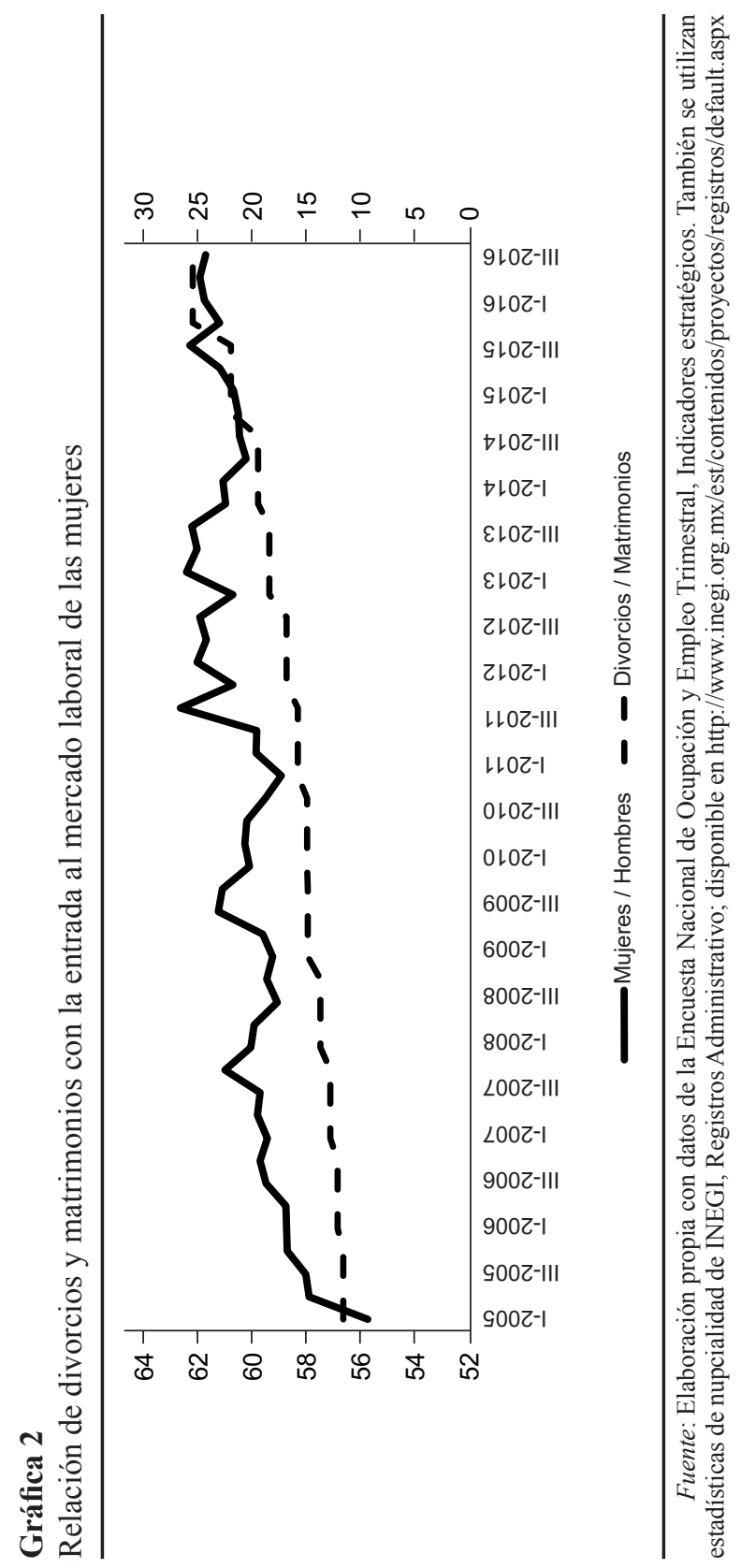




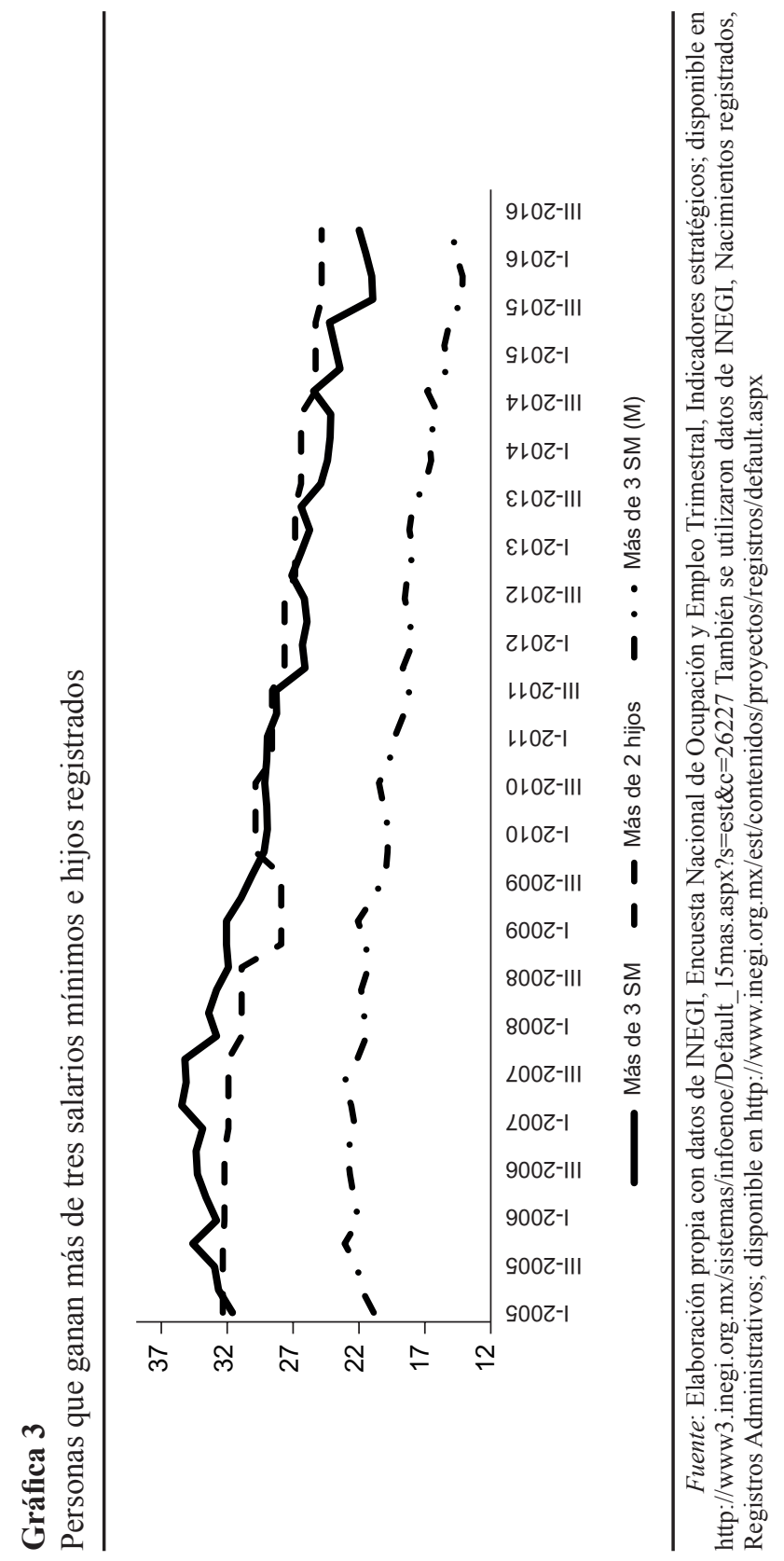


de positivamente en la conformación de hogares tradicionales (biparentales con jefatura masculina).

Finalmente (y no menos preocupante), cada vez son menos los mexicanos y mexicanas de 2005 a 2016 que ganan más de tres SM. Lo anterior prueba la validez del modelo Calidad-Cantidad para el caso mexicano: ante la disminución de ingresos, se tienen menos hijos.

\section{Diversidad de preferencias y efecto de la edad}

En este trabajo se propone que el ingreso y la desigualdad de ingresos son factores importantes en la formación de un hogar monoparental. Sin embargo, la edad es una variable que podría ser fundamental en este análisis. A continuación, se presentan argumentos teóricos a favor de la inclusión de esta variable como un control en los ejercicios estadísticos planteados.

Rivas, Jociles y Moncó (2011) indican que en décadas pasadas las mujeres vivían un destino natural que era la maternidad vinculada al matrimonio para lograr un estatus social y el acceso a la estabilidad económica. También se reconoce que las mujeres no necesitan casarse ni tener hijos para sentirse realizadas, ya que la realización que predomina en la actualidad está centrada en el ámbito profesional y laboral.

La investigadora Catherine Hakim propuso la Teoría de la Preferencia (Hakim, 2000, 2003, 2006; Vitali, Billari, Prskawetz y Testa, 2009), que busca explicar las decisiones de fertilidad sin asumir que todas las mujeres desean ser madres y casarse. Bajo su concepción, las mujeres son las que en realidad controlan la fertilidad en una sociedad, y la comprobación de esta idea (al menos en los países desarrollados) se presenta en la hipótesis de "exprimir el tiempo" (Kreyenfeld, 2002; Gerster, Keiding, Knudsen y Strandberg-Lasen, 2007), que además nos permite explicar por qué el ingreso tiene un doble efecto en las decisiones de fertilidad.

En esta hipótesis, cuando la mujer desea obtener un ingreso ideal, puede postergar la decisión de tener hijos hasta su límite biológico. Si esta mujer desea tener hijos, entonces deberá "exprimir el tiempo", acelerando el número de embarazos y cerrando el tiempo de espera entre los mismos. Este comportamiento es consistente con lo encontrado por Hayford y Guzzo (2011), quienes indican que las mujeres dedican una mayor parte de su edad reproductiva a estar solteras, y conforme van envejeciendo experimentan una presión social relacionada con su reloj biológico.

En la Gráfica 4 se presentan estas ideas en relación con el contexto mexicano. Se muestran series de 1985 a 2016 sobre el porcentaje de naci- 


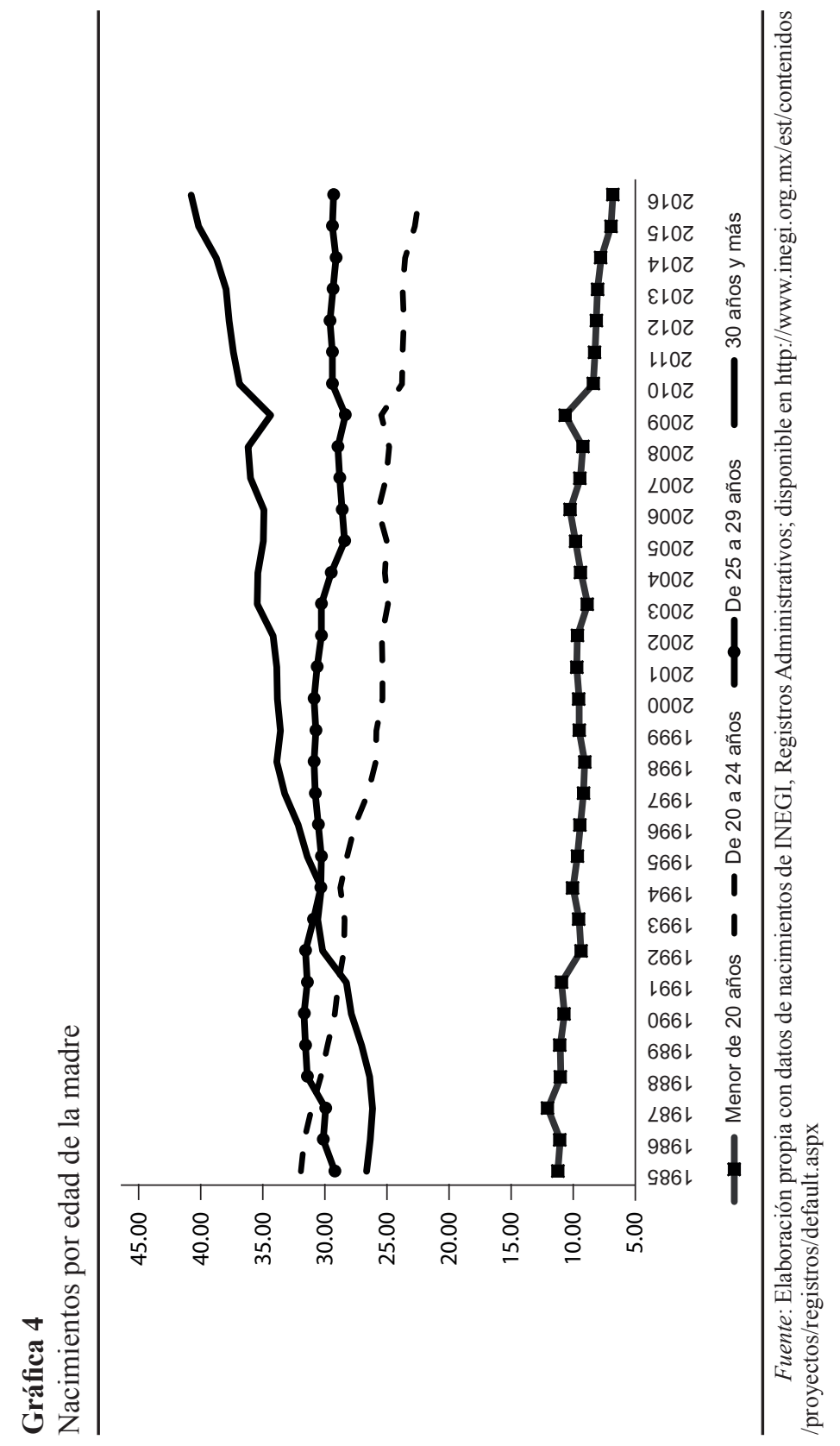


mientos registrados por año de acuerdo con la edad de la madre para el caso de madres que trabajan. Los datos permiten identificar que inicialmente (1985) el mayor porcentaje de nacimientos ocurre en las madres de 20 a 24 años (31.92\%). Para 1988 cambia la tendencia y el mayor porcentaje ocurre en aquellas de 25 a 29 años (31.41\%). Nuevamente, en 1995 se genera otro cambio, ya que la serie que concentra el mayor porcentaje (31.42\%) es la que identifica nacimientos donde la madre reporta 30 años y más. A partir de esta fecha se observa una tendencia positiva en esta serie, lo cual implica que en 2016 el 40.75\% de los nacimientos en México se verifican con mujeres que trabajan y son mayores de 30 años. Como referencia, en 1985 esta condición sólo se verificaba en el $26.63 \%$ de todos los nacimientos registrados. La serie de nacimientos donde la madre trabaja y tiene de 20 a 24 años experimenta una tendencia a disminuir con el tiempo. La serie de nacimientos con mujeres que trabajan y tienen de 25 a 29 años se ha mantenido entre el 6 y el $11 \%$ a lo largo del tiempo, sin mostrar una tendencia marcada, ya sea positiva o negativa. Finalmente, la serie que indica nacimientos en mujeres que trabajan y tienen menos de 20 años se mantuvo constante hasta 2010. A partir de esta fecha presenta una tendencia negativa.

Los datos del INEGI permiten corroborar que, efectivamente, la edad en la cual las mujeres deciden tener hijos en México ha ido en aumento a lo largo del tiempo. Esto es consistente con las ideas relacionadas con el efecto de la edad (i.e., teoría de la preferencia e hipótesis de exprimir el tiempo) en las decisiones de fertilidad de las mujeres.

\section{No quiero pareja o matrimonio, pero sí tener hijos}

La información sobre las sociedades consideradas como desarrolladas indica que la conexión entre el matrimonio y la fertilidad tiende a ser más laxa con el tiempo (Ellwood y Jencks, 2004). Trabajos como el de Gibson-Davis (2011) demuestran, con datos de Estados Unidos, que el deseo de casarse (en particular para las mujeres) disminuye de forma importante a partir de que tienen hijos.

Adicionalmente, se ha encontrado que el aplazamiento u omisión de la decisión de tener hijos puede ser una consecuencia del cambio de las normas sociales y, por lo tanto, no debería estar asociado con el mismo conjunto de estándares que implica el matrimonio. Es normal que se perciba diferente la decisión de tener hijos a medida que la sociedad cambia. En particular, ante nuevas concepciones sobre la idea de tener hijos fuera del matrimonio 
(Thornton y Young-DeMarco, 2001), alcanzar ciertos estándares económicos y sociales (Gibson-Davis, 2011) o bien, particularmente para las mujeres, cuando tener hijos otorga un sentido de vida (Edin y Kefalas, 2011). Dependiendo del cambio de normas, las personas postergan la decisión de casarse tanto como lo deseen, sin que esto repercuta en la intimidad sexual y en la decisión de tener hijos

En estudios como el de Ariza y De Oliveira (2006) se indica que a partir de 1980 en México se experimenta una reducción de la cantidad de hogares considerados como tradicionales (biparentales con hijos), al igual que se reporta en otros países latinoamericanos (Díaz, 2007). Al mismo tiempo, crecen los hogares administrados por una mujer (nucleares sin hijos, unipersonales, y monoparentales). Dentro de las características que se enuncian como factores que pueden incidir en estos tres fenómenos se encuentran: la emigración masculina, la frecuencia del embarazo adolescente, la composición étnica de la población, el nivel de urbanización y el grado de participación de las mujeres en el mercado laboral.

Los datos de la Encuesta Intercensal 2015 del INEGI ${ }^{5}$ en relación con las características de los hogares monoparentales y biparentales muestran un incremento de los primeros. En 2010 representaban 16.8\% del total de hogares familiares, mientras que para 2015 aumentó a 21\%. Adicionalmente, este tipo de hogar se caracteriza por la jefatura femenina. En 2010, el $84 \%$ de los hogares monoparentales estaban dirigidos por una mujer, y en 2015 se reduce un poco (al 81.7\%). ${ }^{6}$ La información del INEGI refuerza que en México existe un aumento en la tendencia de que las personas no quieran vivir con una pareja, pero sí tener hijos. Al mismo tiempo refleja la inercia histórica y cultural, donde para que exista un hogar tradicional (biparental), el jefe de la familia debe ser el hombre. A continuación, se explica cómo inciden las variables de ingreso y la edad de las personas en estas decisiones.

5 Véase http://www.beta.inegi.org.mx/proyectos/enchogares/especiales/intercensal/para conocer los datos de la encuesta. También se puede revisar el boletín de prensa redactado con datos de dicha encuesta en relación con la composición de los hogares en http://www.inegi.org. mx/saladeprensa/aproposito/2017/familia2017_Nal.pdf

6 Véase http://www.inegi.org.mx/saladeprensa/aproposito/2017/familia2017_Nal.pdf 


\section{Metodología}

\section{Hipótesis de trabajo}

Por lo que se ha revisado en la literatura y el análisis de los datos para México, se esperaría encontrar evidencia del impacto del ingreso, la desigualdad de ingresos entre hombres y mujeres, y la edad.

La primera hipótesis de este artículo es que un aumento en el ingreso incide positivamente en la probabilidad de que existan dos tipos de hogares: 1) monoparental con jefatura femenina (González y Molina, 2007; Nicoletti y Tanturri, 2008; Lappegård y Rønsen 2005; Meron y Widmer, 2002; Bongaarts, 2003; Billingsley, 2011), y 2) hogar tradicional (i.e., donde existe un matrimonio con hijos) y con jefatura masculina, tal cual lo reporta Gibson-Davis (2011).

La segunda hipótesis se soporta con el hallazgo de Gibson-Davis (2011) y Smith-Battle (2000) y plantea que la desigualdad de ingresos entre hombres y mujeres incide positivamente en la conformación de hogares tradicionales.

Finalmente, la tercera hipótesis se asocia con el efecto de "exprimir el tiempo" (Kreyenfeld, 2002; Gerster, Keiding, Knudsen y Strandberg-Larsen, 2007). Implica que la interacción del ingreso de las personas y su edad impacta positivamente en el deseo de tener hijos. Se plantea para México que esta interacción deberá incidir positivamente en el establecimiento de hogares monoparentales con jefatura femenina.

\section{Sobre los datos utilizados}

No existe para el país una encuesta especializada que permita analizar la trayectoria de las personas identificando el momento en que deciden tener hijos o vivir con una pareja (i.e., una encuesta panel). En su mayoría, la información que se tiene es a partir de cortes transversales con representatividad estadística a nivel país y para subgrupos de la población (i.e., hombres, mujeres). Dentro de este tipo de instrumentos destaca la Encuesta Nacional de Ingresos y Gastos en los Hogares (ENIGH), que de forma sistemática se realiza cada dos años en el país. ${ }^{7}$

La ENIGH es una encuesta realizada desde 1984 por el INEGI. La población objetivo la constituyen los hogares que residen habitualmente en enigh/

7 Véase http://www.inegi.org.mx/est/contenidos/Proyectos/encuestas/hogares/regulares/ 
viviendas particulares dentro del territorio nacional. El principal objetivo de esta encuesta es conocer el comportamiento de los ingresos y gastos de los hogares, así como las características ocupacionales y sociodemográficas (e.g., edad, educación, ingreso, entre otras) de todos los integrantes del hogar. También se incluyen las características de la infraestructura de la vivienda y su equipamiento. Su tipo de muestreo es probabilístico, por lo que sus resultados pueden generalizarse a toda la población. La muestra utiliza el Marco Nacional de Viviendas del INEGI, construido a partir de información cartográfica y demográfica. Su representatividad es nacional tanto para los estratos urbanos como los rurales.

La principal razón por la cual se utiliza la ENIGH como fuente de información es que es una encuesta con una diversidad de temas y se actualiza con mayor regularidad que un censo o conteo. Adicionalmente, es uno de los instrumentos con mayor calidad estadística del INEGI debido a que a partir de 2008 se han realizado modificaciones sobre su precisión, atendiendo las recomendaciones de la Organización de las Naciones Unidas (ONU).

Mediante este instrumento se pueden identificar hogares monoparentales y conocer para todos ellos las características del jefe o jefa del hogar. Dentro de la ENIGH existe un identificador de parentesco que cubre una cantidad importante de relaciones familiares y no familiares (e.g., servicio doméstico). La codificación de este tipo de relaciones toma como referencia a la jefa o el jefe del hogar. Para conocer las características socioeconómicas de la persona que administra o vive en un determinado hogar, se tiene que cruzar información adicional de otras variables, tales como el género, el número de hijos que tiene, su estado civil, o bien la información en torno a si vive con alguna pareja dentro del mismo hogar.

Mediante los cruces de variables de las diferentes muestras de la ENIGH se ha generado una base de datos a nivel individuo con un total de 430567 observaciones (a nivel jefatura de hogar), de las cuales 83624 corresponden al año 2006 (19.42\%), 123535 a 2008 (28.69\%), 111138 a 2010 (25.81\%), 35533 a 2012 (8.25\%), y finalmente 76737 a 2014 (17.82 por ciento).

\section{Variables}

\section{Variable dependiente}

Para poder entender el proceso que siguen las personas al tener hijos en diferentes arreglos de hogar, se define como dependiente una variable categórica que identifica cada una de las siguientes condiciones: 1) hogar monopa- 
rental, 2) hogar donde existe una pareja con hijos, y 3) hogar con un matrimonio con hijos. Se establece una cuarta categoría (hogar donde la jefa o el jefe es soltero sin hijos) que servirá como punto de partida o categoría de referencia para analizar las demás.

\section{Variables independientes}

En relación con las hipótesis planteadas, tenemos como variables independientes el ingreso y la edad del jefe o jefa del hogar. La variable ingreso representa los ingresos que obtiene el jefe de cada hogar. Cada unidad en la variable representa 10000 pesos para evitar que el coeficiente estimado, aunque sea significativo, tienda a ser cero. Adicionalmente, los valores del ingreso se hacen a precios de 2014, buscando observar los cambios del pasado (2006) a la fecha más próxima posible (2014), sin que repercuta el efecto. El coeficiente de esta variable permite probar la primera hipótesis planteada en el trabajo.

La variable desigualdad permite modelar la inequidad de ingresos en la sociedad mexicana y es la relación del ingreso promedio que tienen los hombres y el ingreso promedio que tienen las mujeres en cada estado de México. El coeficiente estimado de esta variable permite probar la segunda hipótesis del trabajo.

La variable edad en el modelo representa los años cumplidos que tiene la persona, tomando como referencia lo que declara en cada ENIGH. El coeficiente estimado de esta variable permite controlar el efecto parcial de la edad en la decisión de establecer una categoría de hogar. Esta variable también se utiliza para construir la variable de interacción (al multiplicar su valor por el valor de la variable ingreso).

Finalmente, se incluye la interacción ingreso y edad. El coeficiente estimado de esta variable permite probar la tercera hipótesis del trabajo.

\section{Variables de control}

Como variable de control se tiene una que identifica si el hogar se encuentra en una localidad rural (menos de 2500 habitantes). También se tienen 31 variables de respuesta binaria para cada uno de los estados del país con el fin de controlar el efecto de aquellos aspectos idiosincráticos propios de la cultura de cada demarcación territorial en México (e.g., estados más conservadores o liberales). El caso de la Ciudad de México (antes Distrito Federal) se omite a fin de evitar la colinealidad de estas variables, por lo cual su efecto aparecerá en el intercepto que se estime. 
Finalmente, se incluyen como controles variables de respuesta binaria correspondientes a cada año de la muestra de la ENIGH, con excepción de 2014 (i.e., 2006, 2008, 2010 y 2012). Esto último con la finalidad de controlar por efectos coyunturales asociados a un año en particular (e.g., en 2008 existen efectos derivados de la crisis inmobiliaria de Estados Unidos).

\section{Modelo}

La variable dependiente es categórica porque existen más de dos resultados posibles y al mismo tiempo no hay una ordenación natural de cada valor (e.g., el que una persona tenga un matrimonio no es mejor que el que tenga una pareja), por lo cual se utiliza un modelo de regresión logística multinomial (véase el Anexo) en el que los parámetros que se estiman no determinan directamente el efecto marginal de las variaciones de las variables exógenas sobre la probabilidad. Para conocer los efectos marginales es posible realizar una interpretación de la razón de probabilidad definiendo una categoría de referencia. Para los ejercicios estadísticos desarrollados en este trabajo de investigación se ha definido como categoría de referencia el que el hogar sea administrado por una persona que es soltera. Siguiendo la recomendación de Long y Freese (2006), utilizaremos el método Delta para estimar la varianza, errores estándar e intervalos de los parámetros.

El mismo modelo se estima para dos muestras (hogares con jefatura femenina y hogares con jefatura masculina), lo cual permite hacer las comparaciones entre coeficientes. Adicionalmente, se utiliza en las estimaciones una submuestra compuesta por aquellas observaciones donde el jefe o la jefa de hogar cumple con un criterio de edad fértil (definido por el Consejo Nacional de Población, Conapo). Este criterio comprende el intervalo entre los 15 y 49 años de la persona. Si bien para el caso de los hombres podría existir un rango diferente de edad en relación con la fertilidad, es necesario establecer una escala común con la finalidad de realizar comparaciones simples entre hombres y mujeres.

Dado que la categoría de referencia en la variable dependiente es un hogar administrado por una mujer (un hombre) soltera (soltero) sin hijos, lo que se observa como impacto marginal en cada uno de los parámetros es en realidad la razón de probabilidades (odd ratio) que favorece el cambio de una categoría a otra. 


\section{Resultados}

Los resultados del modelo estimado para los hogares con jefatura masculina y femenina se encuentran en el Cuadro 1 . Se discuten y presentan las inferencias de acuerdo con las variables de ingreso, desigualdad de ingresos entre hombres y mujeres y edad. Los resultados de las variables de control se han omitido.

\section{El efecto del ingreso}

Ante un aumento en el ingreso disminuye significativamente la probabilidad de que exista un hogar monoparental con jefatura femenina. Se observa un efecto positivo en la probabilidad de que exista un hogar con jefatura femenina, donde la mujer está casada. Para el caso de los hombres, el ingreso es positivo en el caso de establecer un hogar tradicional (casado con hijos, punto rojo). Se aprecia un efecto negativo cuando aumenta el ingreso en la categoría de hogares administrados por un hombre, que vive con una pareja e hijos.

En relación con la primera hipótesis planteada, se concluye que, ante incrementos en el ingreso, las mujeres deciden establecer un hogar tradicional en lugar de uno monoparental. Este hallazgo coincide con que una mejora en el ingreso de los hombres incrementa la cantidad de matrimonios, tal como lo plantea Gibson-Davis (2011).

\section{El efecto de la desigualdad de ingresos entre hombres y mujeres}

Un aumento en la desigualdad reduce dramáticamente la probabilidad de que existan hogares con jefatura femenina donde se viva en pareja con hijos. Por otro lado, incrementa la probabilidad de que existan hogares donde la mujer esté casada, con hijos y administre dicho hogar. Para los hombres no se reporta un efecto estadísticamente diferente de cero en alguna de las categorías de hogar analizadas. A pesar de ello, existe evidencia de que un aumento de la desigualdad de los ingresos de los hombres en relación con los de las mujeres, favorece el establecimiento de hogares tradicionales. Este hallazgo ya ha sido reportado para otras sociedades por Smith-Battle (2000), pero en su caso se hablaba del efecto en hogares administrados por hombres y no por mujeres. 


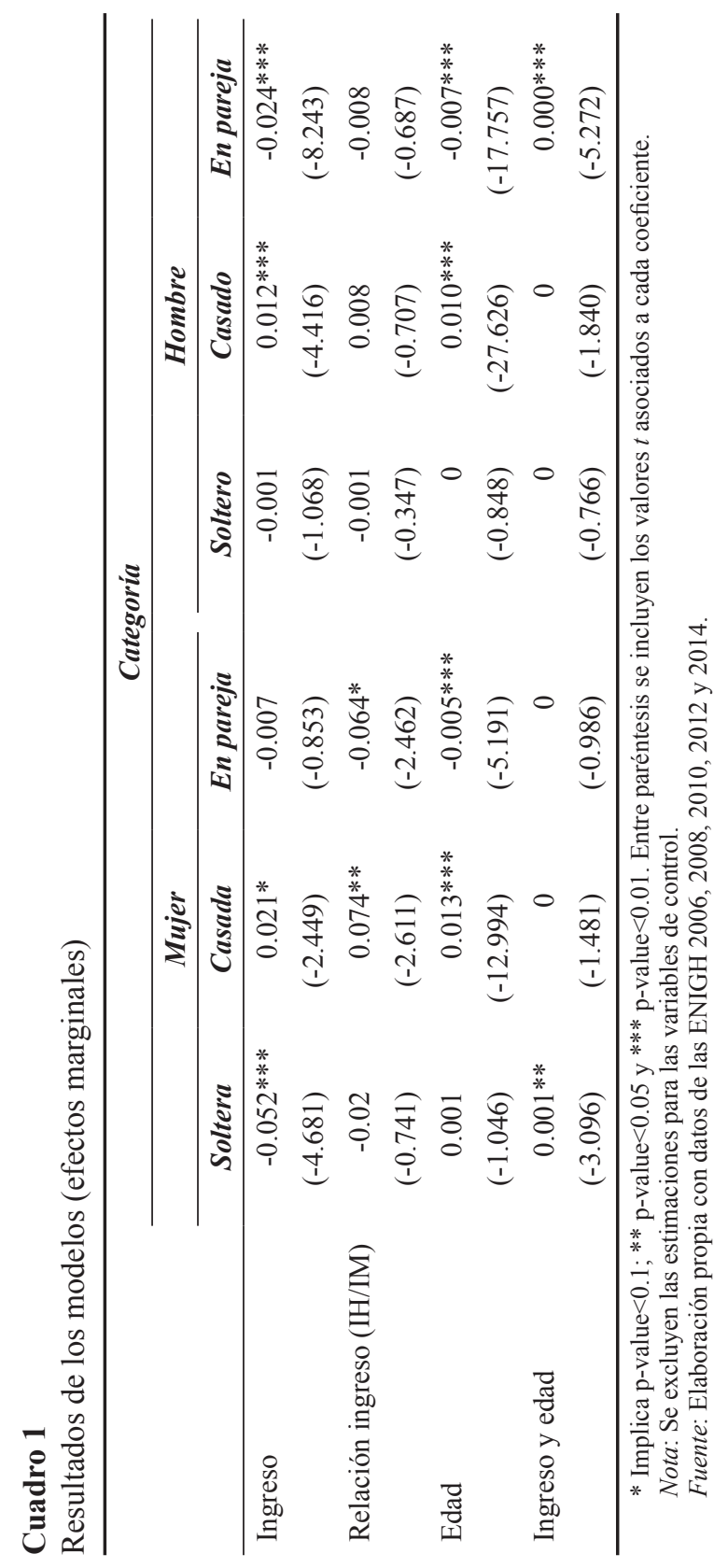




\section{El efecto de la edad}

A mayor edad, se observa un impacto positivo en el establecimiento de hogares donde la mujer está casada con hijos, y un impacto negativo para el caso donde una mujer administra el hogar y decide vivir en pareja con hijos. Esta situación es interesante, pues se podría esperar que el efecto de la edad propiciará el mismo efecto positivo en todos los tipos de hogar. La edad no incide en el establecimiento de hogares monoparentales con jefatura femenina. En otras palabras, al incrementar la edad, las mujeres prefieren formar hogares tradicionales con hijos que vivir con una pareja y tener hijos, o formar un hogar monoparental.

Para el caso de los hogares administrados por hombres, se observan efectos muy similares a los de los hogares administrados por mujeres. Por lo tanto, en el caso de los datos de México se aprecia que un incremento en la edad de las personas favorece el establecimiento de hogares tradicionales por encima de otro tipo de arreglos.

\section{Interacción del ingreso y la edad}

La interacción del ingreso y la edad impacta de forma positiva en la probabilidad de que aparezcan hogares monoparentales con jefatura femenina. Con ello se encuentra evidencia a favor de la tercera hipótesis planteada y se sostiene que en México existe un efecto de "exprimir el tiempo", como el reportado en Kreyenfeld (2002) y Gerster, Keiding, Knudsen y Stranbdberg-Larsen (2007).

\section{En síntesis}

Resumiendo los hallazgos sobre los resultados del modelo, se tiene lo siguiente:

1) El ingreso favorece el establecimiento de hogares tradicionales, pero reduce la probabilidad de acceder a la categoría de hogares con pareja e hijos. Un incremento en el ingreso impacta de forma negativa el establecimiento de hogares monoparentales con jefatura femenina.

2) La desigualdad de ingresos a favor de los hombres favorece el establecimiento de hogares tradicionales y reduce la posibilidad de que se viva en pareja y con hijos. 
3) La edad del jefe del hogar tiene un efecto positivo en la formación de hogares tradicionales, independientemente de si el jefe es hombre o mujer.

4) Las mujeres con mayores ingresos y mayor edad, simultáneamente, prefieren establecer hogares monoparentales.

\section{La persistente inequidad en la formación de hogares con hijos}

Utilizando las estimaciones, se realiza ahora un ejercicio para conocer la evolución de la probabilidad de cada tipo de hogar, a medida que se modifican los valores en las variables de ingreso, desigualdad de ingresos y edad. $\mathrm{Al}$ graficar estas relaciones, podemos conocer cómo interactúa el comportamiento de hombres y mujeres, analizando los cruces de las tendencias estimadas para cada categoría de hogar. Cada gráfica se compone por dos secciones (una para la jefatura masculina y otra para la femenina) y presenta la misma escala tanto para la probabilidad como para la variable independiente analizada.

Una de las primeras inferencias que se puede sustraer de este ejercicio es que las variables de edad e ingreso no afectan de la misma forma a hombres y mujeres en la formación de hogares con hijos. En las tres gráficas se observa que la tendencia a formar un hogar monoparental siempre será diferente en los hombres que en las mujeres. Mientras que en los hombres el efecto prácticamente no existe, en las mujeres se observan efectos importantes, en particular en el caso del ingreso.

Otra inferencia es que la categoría de hogar que tiende a privilegiarse (independiente del tipo de jefatura) es la de hogares donde hay un matrimonio con hijos.

También se observa que el incremento del ingreso no afecta la probabilidad de que un hombre forme un hogar monoparental. En el caso de los hogares administrados por mujeres se observa una situación muy diferente: a un determinado nivel de ingreso, es muy probable que se tenga un hogar monoparental. A medida que se incrementa el ingreso, las mujeres prefieren establecer un hogar tradicional por encima de un hogar monoparental o un hogar con pareja e hijos (véase la Gráfica 5).

En la Gráfica 6 se presenta el efecto de la desigualdad de ingresos en México (IH/IM). En el caso de los hogares administrados por hombres, la desigualdad favorece la generación de un hogar tradicional (matrimonio con hijos). Para las mujeres se identifica que una menor desigualdad (valores más a la izquierda) propicia formar un hogar con una pareja con hijos. Si se 


\section{Gráfica 5}

Cambio en la probabilidad e ingreso
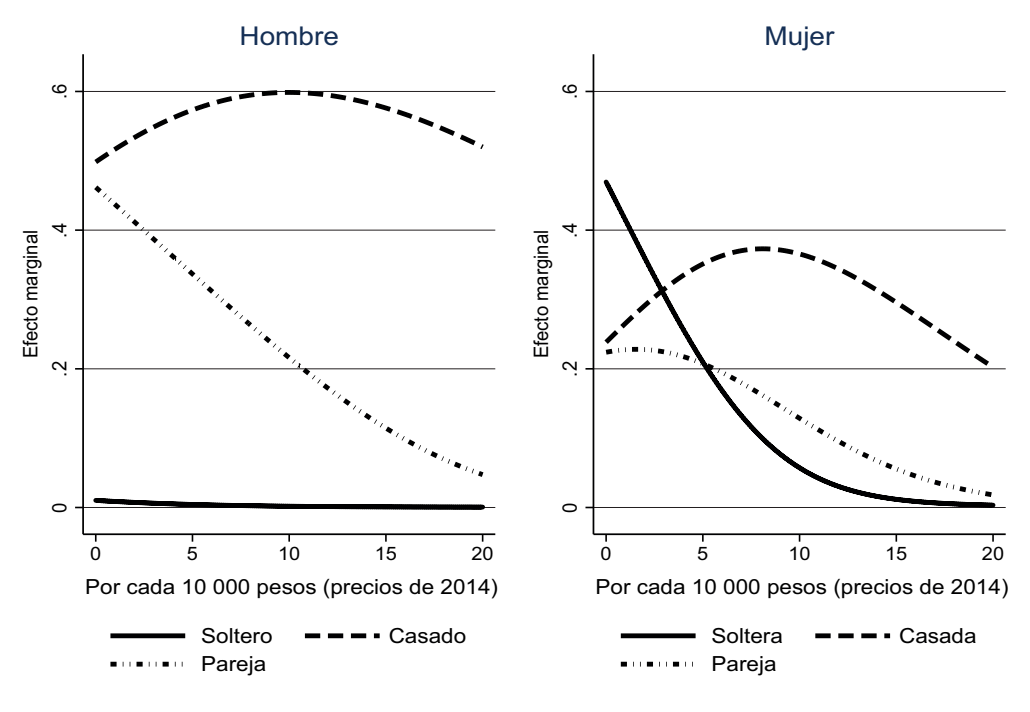

Fuente: Elaboración propia con datos de ENIGH 2006, 2008,2010, 2012 y 2014.

incrementa la desigualdad de ingresos (valores más a la derecha), se observa una tendencia a que se busque establecer un hogar tradicional. Una posible implicación del hallazgo es que, ante la desigualdad de ingresos, las mujeres podrían encontrar adecuado formar un hogar tradicional como una estrategia de supervivencia.

Finalmente, en la Gráfica 6 se tienen las estimaciones en la probabilidad para diferentes años en las personas. En el caso de los hogares administrados por hombres, a menor edad se observa que es más probable la existencia de un hogar donde el hombre tiene hijos y vive en pareja. A medida que aumenta la edad se busca formar un hogar tradicional, y con más edad desciende claramente la tendencia a formar hogares en pareja con hijos. El incremento de la edad en los hombres no motiva la generación de hogares monoparentales.

En cuanto a los hogares administrados por mujeres, se observa que a cierta edad es más probable que se establezcan hogares con una pareja e hijos, y posteriormente hay una tendencia a formar un hogar tradicional. Existen algunas diferencias dignas de comentarse. Antes de los 30 años, una mujer que administra un hogar prefiere establecer un hogar con su pareja e 


\section{Gráfica 6}

Cambio en la probabilidad y desigualdad en ingresos de hombres y mujeres
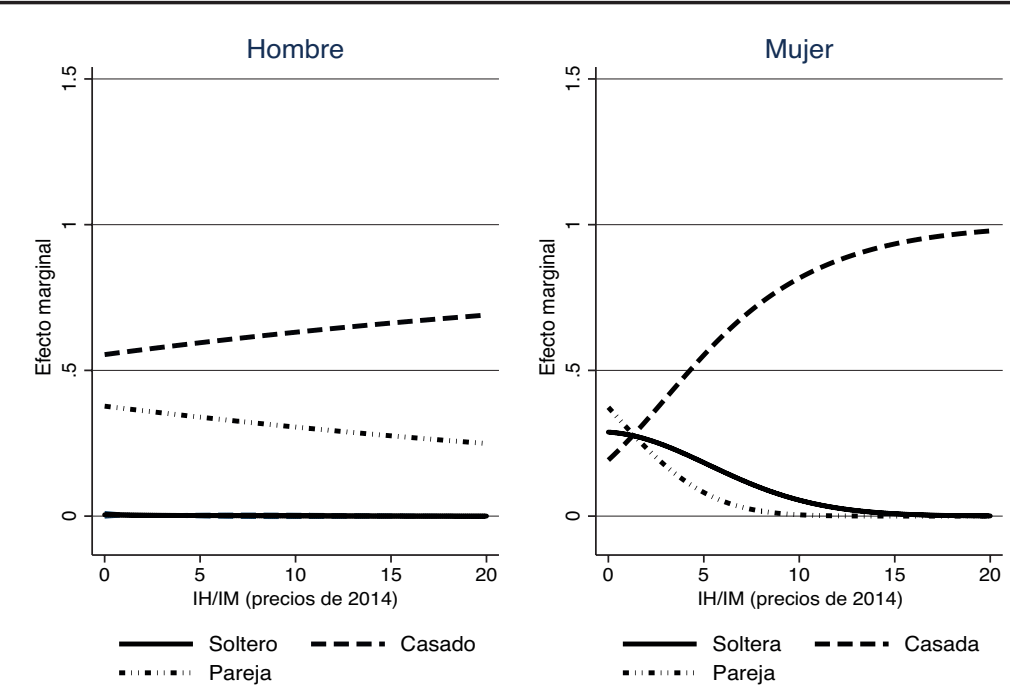

Fuente: Elaboración propia con datos de ENIGH 2006, 2008, 2010, 2012 y 2014.

hijos como primera opción, y en segundo orden de importancia elige integrar un hogar monoparental. Su última opción es formar un hogar tradicional. De forma contrastante, a los 30 años se verifica un cruce de todos los tipos de hogar cuya implicación es que las mujeres prefieren formar hogares tradicionales después de esta edad.

\section{Conclusiones y discusión}

Utilizando datos oficiales de la ENIGH generados por el INEGI en diferentes años $(2006,2008,2010,2012$ y 2014) y un modelo logit multinomial, se ha modelado el comportamiento de hombres y mujeres en un rango de edad que se asume representa el periodo de mayor fertilidad en México (15 a 49 años). El propósito es entender cómo el ingreso, la desigualdad de ingresos y la edad de las personas afectan la conformación de los hogares con hijos. Dentro de los resultados obtenidos, destaca el encontrar que, pese a la ten- 


\section{Gráfica 7}

Probabilidad y edad

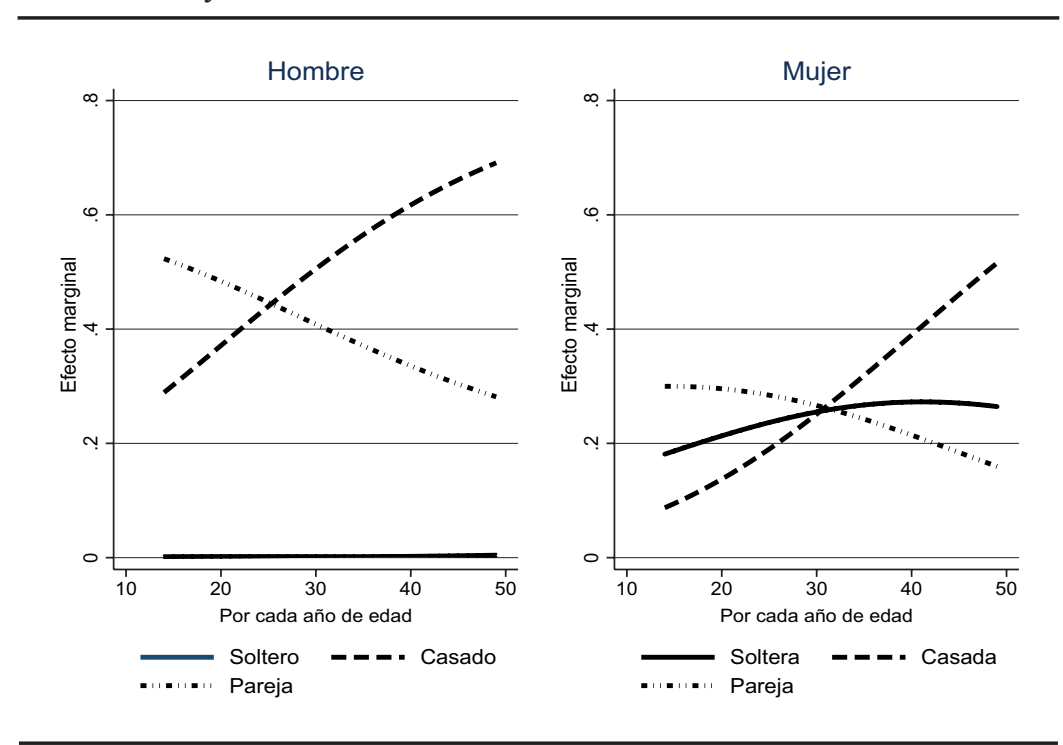

Fuente: Elaboración propia con datos de ENIGH 2006, 2008, 2010, 2012 y 2014.

dencia observada en otras sociedades, las personas prefieren generar hogares tradicionales. Adicionalmente, se reporta un fuerte vínculo entre la desigualdad de ingresos y el establecimiento de un hogar tradicional.

En relación con las hipótesis planteadas se destaca lo siguiente:

- Primera hipótesis: no se encontró evidencia para soportar que el ingreso incide en la formación de un hogar monoparental con jefatura femenina, como lo reportan otros estudios (González y Molina, 2007; Nicoletti y Tanturri, 2008; Lappegård y Rønsen, 2005; Meron y Widmer, 2002; Bongaarts, 2003; Billingsley, 2011). Por el contrario, el efecto del ingreso en la formación de hogares monoparentales con jefatura femenina resulta ser negativo. Sin embargo, se encontró evidencia a favor de que un incremento en el ingreso favorece el establecimiento de hogares donde existe un matrimonio con hijos con jefatura masculina, tal cual lo reporta Gibson-Davis (2011).

- Segunda hipótesis: en cuanto a la desigualdad de ingresos, se llega a la conclusión de que el incremento de esta variable favorece el 
establecimiento de hogares tradicionales, tal cual lo indica SmithBattle (2000). La diferencia es que los datos de México indican que el efecto favorece el establecimiento de hogares tradicionales administrados por mujeres y no por hombres.

- Tercera hipótesis: fue posible identificar un efecto de exprimir el tiempo a favor del establecimiento de hogares monoparentales con jefatura femenina, que se verifica cuando las mujeres tienen más edad y más ingreso, tal cual lo reportan Kreyenfeld (2002) y Gerster, Keiding, Knudsen y Strandberg-Larsen (2007).

Dentro de las limitaciones del trabajo se debe mencionar, en primer lugar, que por el origen de la información no es posible realizar un análisis a escala regional o estatal que pudiera enriquecer la explicación en torno a la generación de hogares monoparentales. Por otro lado, solamente es posible indicar tendencias a nivel agregado (los datos son de corte transversal), pero sería mejor poder conocer trayectorias (si se tuviera un panel de datos). Las dos limitantes pueden resolverse en la medida en que se realicen análisis con un panel de datos, lo cual es posible a partir de la Encuesta Nacional de Ocupación y Empleo (ENOE).

La búsqueda de una mejor sociedad implica que las decisiones de las personas sean autónomas. En este trabajo se esperaba que la desigualdad de ingresos entre hombres y mujeres no influyera en la decisión de establecer un hogar con hijos en México. Dado que no se pudo rechazar la segunda hipótesis, en el trabajo se identifica un fuerte incentivo a que las mujeres que enfrentan desigualdad de ingresos decidan establecer un hogar tradicional como condición para tener hijos.

Lo anterior no significa que las mujeres no puedan elegir otras alternativas (e.g., vivir con familiares o amigos que ayuden a hacerse cargo de los niños o niñas). Implica que un grupo de mexicanas no podrán decidir libremente el número de hijos y el espaciamiento entre los mismos, lo cual es un derecho sexual avalado por la Constitución. ${ }^{8}$ Finalmente, el análisis e interpretación de la información revela que en México persiste la desigualdad de

$8 \mathrm{Al}$ respecto, basta recordar que el artículo 123, fracción VII, de la Constitución Política de los Estados Unidos Mexicanos, indica que “... para trabajo igual debe corresponder salario igual, sin tener en cuenta sexo ni nacionalidad”. Además, el artículo cuarto de la Constitución establece que "...hombres y mujeres son iguales ante la ley" y que dicha ley "protegerá la organización y el desarrollo de la familia". En la Constitución también se establece como un derecho sexual y reproductivo que "...toda persona tiene derecho a decidir de manera libre, responsable e informada sobre el número y el espaciamiento de sus hijos". Véase el "Texto reformado mediante decreto publicado en el Diario Oficial de la Federación el 31 de diciembre de 1974", disponible en http://www.diputados.gob.mx/LeyesBiblio/pdf/1_240217.pdf 
ingresos en contra de las mujeres y que esta condición macroeconómica se traslada a una desigualdad en el hogar.

\section{Anexo}

Modelo de regresión logística multinomial

El modelo utilizado es logit multinomial. Este tipo de modelo se estima mediante máxima verosimilitud. Matemáticamente se tiene lo siguiente:

$$
P(y=j \mid x)=\frac{\exp \left(x \beta_{j}\right)}{\left[1+\sum_{h=1}^{j} \exp \left(x \beta_{h}\right)\right]}
$$

donde $y$ es una variable aleatoria $j=1,2, \ldots, 4$.

El valor de $j=1$ es para identificar la jefatura de hogar donde la persona es soltera sin hijos (categoría de referencia), $j=2$ es para indicar la jefatura de hogar donde la persona es soltera con hijos, el valor de $j=3$ es para la jefatura de hogar donde la persona vive en pareja con hijos, y el valor de $j=4$ es para la jefatura de hogar donde la persona es casada con hijos; $x$ es un vector de variables independientes y de control.

Dado que las probabilidades de todas las categorías en la variable dependiente deben sumar uno, se espera que:

$$
P(y=0 \mid x)=\frac{1}{\left[1+\sum_{h=1}^{j} \exp \left(x \beta_{h}\right)\right]}
$$

Esto implica que los coeficientes estimados dependen de la alternativa considerada como referencia. En el caso del trabajo, esta categoría de referencia, como se ha comentado, es $j=1$ (jefatura de hogar donde la persona es soltera sin hijos). Los efectos parciales en las variables indican en todo caso la relación de probabilidades de alguna de las otras categorías y la categoría de referencia. 


\section{Bibliografía}

Ariza, M. y De Oliveira, O. (2006). Regímenes sociodemográficos y estructura familiar: los escenarios cambiantes de los hogares mexicanos. Estudios Sociológicos, 24(70), 3-30. Recuperado de https://www.jstor.org/ stable/40421023?seq=2\#page_scan_tab_contents

Becker, G. S. (1974). A theory of marriage. In economics of the family: Marriage, children, and human capital. Cambridge, MA: UMI.

Becker, G. (1981). A treatise on the family. Cambridge, MA: Harvard University Press.

Becker, G. S. y Lewis, H. G. (1973). On the interaction between the quantity and quality of children. Journal of Political Economy, 81(2), S279S288. Recuperado de https://www.jstor.org/stable/1840425?seq=1\#page_ scan_tab_contents

Bergstrom, T. (1989). A fresh look at the rotten kid theorem and other household mysteries. Journal of Political Economy, 97(5), 1138-1159. Recuperado de https://www.jstor.org/stable/1831889?seq=1\#page_scan_tab_ contents

Billingsley, S. (2011). Second and third births in Armenia and Moldova: An economic perspective of recent behavior and current preferences. European Journal of Population, 27(2), 125-155. Recuperado de https:// link.springer.com/article/10.1007/s10680-011-9229-y

Blake, J. (1968). Are babies consumer durables? A critique of the economic theory of reproductive motivation. Population Studies, 22(1), 5-25. Recuperado de https://www.tandfonline.com/doi/pdf/10.1080/0032472 8.1968.10405523? needAccess $=$ true

Bongaarts, J. (2003). Completing the fertility transition in the developing world: The role of educational differences and fertility preferences. Population Studies, 57(3), 321-336. Recuperado de https://www.jstor. org/stable/3595729?seq=1\#page_scan_tab_contents

Browning, M., Chiappori, P. A. y Weiss, Y. (2014). Economics of the family. Cambridge University Press.

Carbone, J. y Cahn, N. (2014). Marriage markets: How inequality is remaking the American family. Oxford University Press.

Consejo Nacional de Población (Conapo) (2009). Informe de ejecución del Programa de Acción de la Conferencia Internacional sobre la Población y el Desarrollo, 1994-2009. Recuperado de http://www.conapo.gob.mx/ es/CONAPO/Informe_de_Ejecucion_Programa_de_Accion_de_la_Con ferencia_Internacional_sobre_la_Poblacion_y_el_Desarrollo_19942009 
González de la Rocha, M. (1999). Hogares de jefatura femenina en México: patrones y formas de vida. En M. González de la Rocha (ed.), Divergencias del modelo tradicional: hogares de jefatura femenina en América Latina (pp. 125-151). Ciudad de México: CIESAS / SEP / Conacyt / Plaza y Valdés.

Díaz, P. I. U. (2007). Familias monoparentales con jefatura femenina, una de las expresiones de las familias contemporáneas. Revista Tendencias y Retos, 12, 81-90. Recuperado de http://www.ts.ucr.ac.cr/binarios/ revistas/co/rev-co-tendencias-0012-05.pdf

DiPrete, T. A. y Buchmann, C. (2006). Gender-specific trends in the value of education and the emerging gender gap in college completion. Demography, 43(1), 1-24. Recuperado de https://link.springer.com/content/ pdf/10.1353\%2Fdem.2006.0003.pdf

Edin, K. (2000). What do low-income single mothers say about marriage? Social Problems, 47(1), 112-133. Recuperado de https://academic.oup. com/socpro/article/47/1/112/1619375?searchresult=1

Edin, K. y Kefalas, M. (2011). Promises I can keep: Why poor women put motherhood before marriage. Berkeley, CA: University of California Press.

Ellwood, D. T. y Jencks, C. (2004). The spread of single-parent families in the United States since 1960. Cambridge, MA: Harvard University, John F. Kennedy School of Government.

Esteinou, R. (2014). Fragilidad y recomposición de las relaciones familiares. A manera de introducción. Desacatos. Revista de Antropología Social, 2, 11-26. Recuperado de http://www.scielo.org.mx/pdf/desacatos/n2/ n2a2.pdf

García, B. y Rojas, O. (2002). Los hogares latinoamericanos durante la segunda mitad del siglo XX. Una perspectiva sociodemográfica. Estudios Demográficos y Urbanos, 17(2), 261-288. Recuperado de http://estu diosdemograficosyurbanos.colmex.mx/index.php/edu/article/view/1139/ 1132

Gerster, M., Keiding, N., Knudsen, L. B. y Strandberg-Larsen, K. (2007). Education and second birth rates in Denmark 1981-1994. Demographic Research, 17, 181-210. Recuperado de https://www.demographic-re search.org/volumes/vol17/8/17-8.pdf

Gibson-Davis, C. (2011). Mothers but not wives: The increasing lag between nonmarital births and marriage. Journal of Marriage and Family, 73(1), 264-278. Recuperado de https:/onlinelibrary.wiley.com/doi/ epdf/10.1111/j.1741-3737.2010.00803.x

González, E. y Molina, T. (2007). Características de la maternidad adoles- 
cente de madres a hijas. Revista Chilena de Obstetricia y Ginecología, 72(6), 374-382. Recuperado de https://scielo.conicyt.cl/pdf/rchog/v72n6/ art04.pdf

Hakim, C. (2000). Work-lifestyle choices in the 21st century: Preference theory. Oxford University Press.

Hakim, C. (2003). A new approach to explaining fertility patterns: Preference theory. Population and Development Review, 29(3), 349-374. Recuperado de https://www.jstor.org/stable/3115278?seq=1\#page_scan_tab_ contents

Hakim, C. (2006). Women, careers, and work-life preferences. British Journal of Guidance and Counselling, 34(3), 279-294. Recuperado de https:// www.tandfonline.com/doi/full/10.1080/03069880600769118?scroll=to $\mathrm{p} \&$ needAccess $=$ true

Hayford, S. R. y Guzzo, K. B. (2011). The myth of the middle-class single mother: Decomposing demographic change in nonmarital fertility, 1988-2008 (Working Paper Series, 2011-09). Bowling Green State University, Center for Family and Demographic Research.

Kreyenfeld, M. (2002). Time-squeeze, partner effect or self-selection? An investigation into the positive effect of women's education on second birth risks in West Germany. Demographic Research, 7(2), 15-48. Recuperado de https://www.demographic-research.org/volumes/vol7/2/72.pdf

Landero, R. (2001). Las familias monoparentales: sus características y tipología. Revista de Ciencias Sociales, 4(90-91), 9-23. Recuperado de http:// www.redalyc.org/pdf/153/15318269012.pdf

Lappegård, T. y Rønsen, M. (2005). The multifaceted impact of education on entry into motherhood. European Journal of Population / Revue Européenne de Démographie, 21(1), 31-49. Recuperado de https://link. springer.com/content/pdf/10.1007\%2Fs10680-004-6756-9.pdf

Liefbroer, A. C. y Corijin, M. (1999). Who, what, where, and when? Specifying the impact of educational attainment and labour force participation on family formation. European Journal of Population / Revue Européenne de Démographie, 15(1), 45-75. Recuperado de https://link.springer. com/content/pdf/10.1023\%2FA\%3A1006137104191.pdf

Lindbeck, A. y Weibull, J. W. (1988). Altruism and time consistency: The economics of fait accompli. Journal of Political Economy, 96(6), 11651182. Recuperado de https://www.jstor.org/stable/1831946?seq=1\#page_ scan tab_contents

Liu, J. (2015). Does the rise of inequality of income -as measured by Gini coefficient have a negative effect on the marriage rate? Evidence of as- 
sortive mating in USA using fixed-effect model. Journal of Applied Economics \& Business Research, 5(2), 74-84. Recuperado de http:// www.aebrjournal.org/uploads/6/6/2/2/6622240/jaebr-2015-74.pdf

Long, J. S. y Freese, J. (2006). Regression models for categorical dependent variables using Stata. College Station, TX: Stata Press.

López, M. P. e Izazola, H. (1994). El perfil censal de los hogares y las familias en México. Monografías censales de México. Ciudad de México: INEGI / Secretaría de Salud / UNAM.

López-Ruiz, L., Esteve, A. y Cabré, A. (2009). Uniones consensuales y matrimonios en América Latina: ¿dos patrones de homogamia educativa? Papeles de Población, 15(60), 09-40. Recuperado de http://www. scielo.org.mx/pdf/pp/v15n60/v15n60a2.pdf

Martin, T. C. y Juárez, F. (1995). The impact of women's education on fertility in Latin America: Searching for explanations. International Family Planning Perspectives, 21(1), 52-80. Recuperado de https://www.jstor. org/stable/2133523?seq=6\#page_scan_tab_contents

Meron, M. y Widmer, I. (2002). Unemployment leads women to postpone the birth of their first child. Population, 57(2), 301-330. Recuperado de https://www.persee.fr/doc/pop_1634-2941_2002_num_57_2_18394

Nicoletti, C. y Tanturri, M. (2008). Differences in delaying motherhood across European countries: Empirical evidence form the ECHP. European Journal of Population / Revue Européenne de Démographie, 24(2), 157-183. Recuperado de https://link.springer.com/article/10.1007/ s10680-008-9161-y

Piani, G. (2003). ¿Quién se casa con quién? Homogamia educativa en las parejas de Montevideo y Zona Metropolitana (Documento de trabajo, 13-03). Recuperado de https://www.colibri.udelar.edu.uy/jspui/bits tream/123456789/1986/1/DT\%20E\%202003-13.pdf

Rivas, A. M., Jociles, M. I. y Moncó, B. (2011). Las madres solteras por elección. ¿Ciudadanas de primera y madres de segunda? Revista Internacional de Sociología, 69(1), 121-142. Recuperado de http://revintso ciologia.revistas.csic.es/index.php/revintsociologia/article/view/360/366

Smith-Battle, L. (2000). The vulnerabilities of teenage mothers: Challenging prevailing assumptions. Advances in Nursing Science, 23(1), 29-40. Recuperado de https://journals.lww.com/advancesinnursingscience/ Abstract/2000/09000/The_Vulnerabilities_of_Teenage_Mothers_.7.aspx Thornton, A. y Young-DeMarco, L. (2001). Four decades of trends in attitudes toward family issues in the United States: The 1960s through the 1990s. Journal of Marriage and Family, 63(4), 1009-1037. Recuperado de https:// onlinelibrary.wiley.com/doi/epdf/10.1111/j.1741-3737.2001.01009.x 
Torche, F. (2010). Educational assortative mating and economic inequality: A comparative analysis of three Latin American countries. Demography, 47(2), 481-502. Recuperado de https://link.springer.com/article/10.1353/ dem.0.0109

Torche, F. (2015). Intergenerational mobility and gender in Mexico. Social Forces, 94(2), 563-587. Recuperado de https://academic.oup.com/sf/ article/94/2/563/2583798

Tuirán, R. (1993). Vivir en familia: hogares y estructura familiar en México, 1976-1987. Comercio Exterior, 43(7), 662-676. Recuperado de http:// revistas.bancomext.gob.mx/rce/magazines/248/8/RCE8.pdf

Welti Chanes, C. (2000). Análisis demográfico de la fecundidad adolescente en México. Papeles de Población, 6(26), 43-87. Recuperado de http:// www.scielo.org.mx/pdf/pp/v6n26/v6n26a4.pdf

Vitali, A., Billari, F. C., Prskawetz, A. y Testa, M. R. (2009). Preference theory and low fertility: A comparative perspective. European Journal of Population / Revue Européenne de Démographie, 25(4), 413-438. Recuperado de https://link.springer.com/content/pdf/10.1007\%2Fs10680009-9178-x.pdf

\section{Acerca del autor}

Ignacio Ibarra López es doctor en Economía por la Fundación Universidad de las Américas Puebla. Actualmente es director de la licenciatura en Economía de la Escuela de Ciencias de Gobierno del campus Puebla del Tecnológico de Monterrey. Ha realizado trabajos de consultoría en materia de políticas públicas, principalmente en la evaluación de programas sociales, como el Programa Escuelas de Tiempo Completo y el Programa PESA-FAO. En 2013 diseñó la Estrategia Integral para el Combate de la Pobreza en Puebla. Durante 2017 participó como asesor en temas de estadística para el Grupo Técnico de la Canasta Básica de Alimentos (GT-CBA) para la Comisión Centroamericana de Estadísticas del Sistema de Integración Centroamericana (SICA). Obtuvo el segundo lugar del Tercer Premio Nacional de Investigación "Impulso al desarrollo de las finanzas públicas estatales", otorgado por PwC, Interacciones y UNAM (2017). ORCID: https://orcid. org/0000-0002-0371-3976

Es autor de diversos artículos científicos sobre aspectos conductuales relacionados con la toma de decisiones de las personas. Entre sus publicaciones destaca: 
Ibarra, I., Pérez Serrano, A., y Cuecuecha Mendoza, M. P. (2019). Búsquedas en Internet y su influencia en los flujos de turistas y visitantes. El caso del avistamiento de luciérnagas en Nanacamilpa Tlaxcala. El Periplo Sustentable, 36, 402-431. Disponible en https://rperiplo.uaemex.mx/ article/view/9430

Recepción: 25 de junio de 2017.

Aceptación: 24 de abril de 2018. 
